DOI: $10.22559 /$ folklor.881

folklor/edebiyat, cilt:25, sayı:99, 2019/3

\title{
Ankara ve Konya'da Yaşayan Nogay Türklerinde Şınlar Üzerine Bir Araştırma
}

\author{
A Research on Şins in Nogay Turks Living in \\ Ankara and Konya
}

\section{Muhittin Çelik ${ }^{*}$ \\ Süleyman Hilmi Kızıldağ}

\section{Öz}

Araştırmamıza konu olan Nogay Türkleri, ata yurtlarının Kafkasya olduğu bilinen ve 19. yüzyılın ortalarında Rusların çeşitli baskıları neticesinde Ankara ve Konya'ya göç eden bir Türk topluluğudur. Nogaylar konuştukları Nogay Türkçesiyle, çoğunluğu sözlü olmak üzere, birçok edebi ürün meydana getirmişlerdir. $\mathrm{Bu}$ edebi ürünlerin biri de kendine özgü özellikleriyle yüzyıllardır bir gelenek içinde gelişerek günümüze kadar gelmiş olan şınlardır. Bu çalışmada öncelikle şın ve şınŞ1 sözcügünün etimolojisi incelenmiştir. Bu sözcüklerin diğer Türk lehçelerindeki telaffuzları ve anlam karşılıkları araştırılmıştır. Nogay sözlü edebiyatında karşılıklı beyitler söylemeye dayalı bir nazım şekli olan şınlar ve şınşılık geleneği hakkında bilgiler verilmiştir. Daha sonra şın söyleyen kişiler olan şınşıların özelliklerine dair bilgiler sunulmuştur. Ayrıca şınların şekilsel özellikleri ve söylenme amaçları hakkında da bilgiler sunulmuştur. Bu bilgiler Nogay köylerinden yapılan derlemelerden örnekler verilerek desteklenmiştir. Dünyada Nogay Türkçesini konuşan insan sayısının gittikçe azaldığını göz önünde bulundurduğumuzda yapılan bu

Dr. öğretim üyesi, İnönü Üniversitesi, Fen Edebiyat Fakültesi, Türk Dili ve Edebiyatı Bölümü muhittin.celik@inonu.edu.tr

** Doktora öğrencisi, İnönü Üniversitesi, Sosyal Bilimler Enstitüsü, Türk Dili ve Edebiyatı Anabilim Dalı, shkizildag@gmail.com 
derlemelerin önemli olduğunu düşünmekteyiz. Çalışmamız, Nogay Türkçesinin unutulmamasına yardımcı olmak ve zengin sözlü edebi ürünlerinin tanıtılmasını sağlamak amacıyla atılan bir adımdır.

Anahtar sözcükler: Nogay Türkleri, Nogay Türkçesi, şın, şınşı

\begin{abstract}
Nogay Turks, the subject of our research, is a Turkish community known as the ancestral homeland known to the Caucasus and migrating to Ankara and Konya in the mid-19th century under the various pressure of Russians. The Nogays brought many literary items to the square with the Nogay Turkish talk they talked about, mostly verbal. One of these literary products is şins, which have grown up in a tradition with their own characteristics and come up to daylight. In this study, the etymology of the word şin and şinşi has been examined. Pronouns and meanings of these words in other Turkish dialects were investigated. We have given information on Nogay's oral literature şins and tradition of şins, which is a form of verse based on mutual couplets. Then, the information about the characteristics of the şinşi>s is presented. In addition, information has been provided about the characteristic features of the şins and the purposes of being told. This information has been supported by giving examples from compilations made by Nogay villagers. Considering that the number of people speaking Nogay in the world is decreasing, we think that these compilations are important. Our work is a step in order to help Nogay Turkish not to be forgotten and to promote the introduction of rich verbal literary products.
\end{abstract}

Keywords: Nogay Turks, Nogay Turkish, şın, şınşı

\title{
Giriş
}

Tarihi süreç içerisinde Türk dilinin geniş bir alana yayılması çeşitli lehçelere ayrılmasına neden olmuştur. Bu lehçelerden biri olan Nogay Türkçesi, bir Türk topluluğu olan Nogay Türkleri tarafından konuşulmakta ve bu lehçeyle edebi ürünler meydana getirilmektedir.

Nogay Türkleri şu an dünyanın çeşitli yerlerinde yaşayan ancak nüfus açısından sayıları önemli derecede azalmış olan bir Türk topluluğudur. Ata yurtları Kafkasya olan Nogay Türkleri Türkiye'ye 1860'lı yıllarda göç etmeye başlamıştır. Türkiye'ye göç eden Nogaylar üzerine çeşitli araştırmalar yapılmıştır. Bu araştırmalar çoğunlukla tarihi ve lengüistik çalışmalardır. Bir milletin bütünüyle incelenebilmesi için o milletin edebi ürünlerinin de derlenmesi ve bu derlemelerin üzerinde çalışılması gerekmektedir.

Sıqaliyev'e göre Nogay Türkleri edebi ürünler içerisinden manzum eserleri, mensur eserlerden daha değerli saymışlardır (1975'ten aktaran Akbaba, 2009: 28). Manzum ürünler ise Rusların Nogaylar üzerindeki kendi yazı dilleriyle eser meydana getirmeme yönündeki baskıları yüzünden yalnızca sözlü edebi gelenek içinde gelişebilmiştir. Nesilden nesle aktarılarak can bulan sözlü edebi ürünler aslında suya işlenmiş birer sanat eserleridir. Bu ürünleri ebru sanatı inceliğinde yapılacak çalışmalarla yazıya aktarmaz isek zamanın dalgalarında kaybolup hafizalardan silinebilirler. 
Bu çalışmada, öncelikle şın ve şınşı sözcüğünün etimolojisi hakkında bilgi verip Nogay sözlü edebiyatında karşılıklı beyitler söylemeye dayalı bir nazım şekli olan şınları ve şınşılık geleneğini incelemeye çalışacağız. Ayrıca şınların şekilsel özellikleri ve söylenme amaçları hakkında Nogay köylerinden yaptığımız derlemelerden örnekler vererek bilgiler vermeye çalışacağız. Örneklerin, aynı satırda sağ tarafına Türkiye Türkçesine aktarımını vereceğiz.

\section{I. Şın ve Şınşı kelimesinin etimolojisi}

Nogay Türklerinde şın nazım türünü söyleyen kişilere halk arasında şış̧ı denir. Günümüzde şış̧1 sözcüğünün Tatar, Kazak, Kırgız, Özbek ve Türkmen Türkçesi gibi Türk lehçelerinde sınçı, çınçı gibi farklı telaffuzları olmakla beraber, şınşı sözcüğü bu lehçelerde de varlığını sürdürmektedir. Sözcük, şın isim köküne Nogay Türkçesinde isimden isim yapım eki olan ve isimlere meslek olma hüviyeti kazandırabilen -şı ekinin getirilmesiyle oluşmuştur. Ayrıca şın isim köküne, isimden fiil yapım eki olan -la ekinin getirilmesiyle de icra edilen

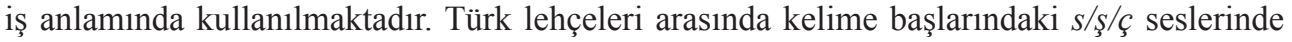
telaffuz farklılıkları olabilmektedir. Bu ses özelliklerini dikkate alarak araştırmamızı yaptık. Buna göre:

Runik harfli eski Türkçe metinlerinde birçok yerde geçen $s l$-, $s ı n$ - sözcükleri "kır-, k1rıl-“ anlamlarında kullanılmaktadır. Tariat ve Karı Çor Tegin (Xi'an) yazıtlarında geçen sın sözcügünü ise Clauson, iki farklı maddede ele almıştır. Clauson, sözcügün ilk maddesinde sözcüğe "vücudun azaları" ve "boy bos" anlamlarını vermiştir. Sözcüğün ikinci maddesinde sözcüğe "mezar" anlamını vermiş ve bu sözcüğün Çince'den gelmiş olabileceğini belirtmiştir (Clauson, 1972: 832). Gabain sözcüğün sın veya sin şeklinde okunabileceğini belirtmiş ve sözcüğe "vücudun azaları" anlamını vermiştir (Gabain, 1988: 293). Ayrıca Gabain sin sözcüğünün Çince (siěn) olabileceğini belirtir ve sözcüğe "türbe" anlamını da verir (Gabain, 1988: 294). Tekin $\sin$ sözcügüne "mezar" anlamını verir ve sözcüğün Çince olduğunu belirtir (Tekin, 2003: 252). Aydın sın sözcügüne “mezar, kabir” anlamını verir. Aydın’a göre sin sözcüğü Karı Çor Tegin (Xi’an) yazıtında art ünlülü yazılmıştır. Bundan dolayı Aydın, Tariat yazıtında tanıklanan sin sözcüğünün aslında doğru biçiminin sın olması gerektiğini ifade etmektedir (Aydın, 2013: 163).

Kutadgu Bilig'de sın kelimesi “boy bos, kılık” anlamlarında, Kutadgu Bilig'de sınçı kelimesi ise "insanın dış görünüşüne bakarak o insanın karakterini söyleyebilen uzman kişi” anlamında kullanılmıştır (Arat, 1979: 396).

Divanu Lugati’t-Türk'e baktığımızda kelimenin anlamıyla ilgili şu sonuç ortaya çıkmaktadır: çın: doğru, güvenilir, doğruluk. çınla-: gerçek olduğunu tasdik etmek, doğrulamak. sın: uzunluk ve boy bos. sına-: sınamak, denemek. sın: sinek vizıltısı, kulak çınlaması (Ercilasun, Akkoyunlu, 2015). Bu son anlam ile kelimenin yansıma bir sözcük olduğu düşünülebilir.

Nogayca-Rusça sözlükte şınşı kelimesi "batıl inanışları çok olan insan; casus ispiyoncu” anlamlarına gelmektedir (Baskakova, 1968: 321). K. K. Yudahin'in Kırgızca-Rusça sözlüğünde sınşı şeklinde geçen kelimenin hangi anlamları karşıladığı verilmiştir. Buna göre kelime kökü olan sın+: deneme, sınama; eleştiri, tenkit; kendi kendini tenkit; dikkatle incelemek anlamlarını karşılamaktadır. Sınçı kelimesi ise tenkit eden, edebiyat tenkitçisi; atların kalite- 
lerini ve özelliklerini tahmin edebilen kişi anlamlarına gelmektedir (1985'ten aktaran Temur, 2014: 25).

Kazan Tatarcasında çınçı olarak görülen kelimenin kökü çın+ dır ve hakiki, gerçek, doğru; gerçeklik; yapma olmayan; ideal olan anlamlarına gelmektedir. Çınçı hakikatleri söyleyen kişi; çınla- ise sesini duyurmak anlamlarına gelmektedir. Kırım Tatarcasında da kelime yine çın ve çınla- şeklinde kullanılmaktadır.

Özbek Türkçesinde sınçı "atların yaşını ve diğer özelliklerini iyi bilen kişi” olarak geçmektedir (1981'den aktaran Temur, 2014: 26). Söz konusu kelime Altay Türkçesinde şinçüçi şeklinde geçmektedir. Saha Türkçesinde çinçi şeklinde kullanılan kelime "elle yoklama, elle yoklayarak tetkik etme, etraflıca araştırma, inceleme, işaret, meçhuliyetin alameti" anlamlarına gelmektedir. Çinçi isim gövdesi - hit isimden isim yapma ekini alarak çinçihit kelimesini oluşturmuştur. Kelime "istikbali kestirebilen adam, kâhin” anlamlarını karşılamaktadır. (1945'ten aktaran Temur, 2014: 27).

Görüldüğü üzere Türk dünyasının birçok yerinde şın ve şınşı kavramı "doğru, gerçek, gerçekleri söyleyen, münekkit, kâhin, insanlar ve hayvanların özelliklerine göre kalitesini ön görebilen, ses çıkartan kişi” anlamlarında kullanılmıştır. Bunları birleştirdiğimizde genel olarak şınşı kelimesinin, birincisi kulağa hoş gelen beyitlerle insanlara seslenen ve ikincisi çeşitli konularda gelecekte oluşabilecek özelliklerle ilgili insanlara doğruları söylemeye çalışan kişi olmak üzere iki boyutu vardır.

Köprülü, Türklerin İslâmiyetten önceki devirlerde, dini inançları gereği yaptıkları merasimlerde halk şairlerinin de bulunduğunu ve bunların toplumda önemli bir mevkide oldukları$\mathrm{n}$ belirterek İslâm dinine girdikten sonra da bu halk şairlerinin halk arasında çeşitli görevlerde eski gelenekleri devam ettirdiklerini belirtir (Köprülü, 1989: 159-161). İslamiyetten önceki halk şairlerinin dînî fonksiyonları zamanla mutasavvıflara isnat olunmuştur. Türk halk şairlerinin içtimaî iş bölümü neticesinde yavaş yavaş görev alanları daralmış; şairlik, büyücülük, müneccimlik ve ruhanîk birbirlerinden ayrılmıştır (Azar, 2007: 123). Türklerin İslâmiyeti kabul etmesi ve halk ozanlarının dînî işlevselliklerinin mutasavvıflara geçmesiyle şınşı kelimesi zamanla "kulağa hoş gelen beyitlerle insanlara seslenen kişi”" anlamını karşılar olmuştur.

\section{II. Şınşılık geleneği ve şınşıların özellikleri}

Yaptığımız derlemelere göre Nogaylar iki çeşit şın söylerler. Birinci şınlar, halkın içinden çıkmış ozanların belli bir seyirci önünde atışmak amacıyla söyledikleridir. Bu şınları söyleyenlere halk arasında şınşı denir. İkinci şınlar ise evlenme çağına gelmiş erkekler ile kızların kendi aralarında karşılıklı söyledikleri şınlardır. Bunları dile getirerek sürdürmeye şınşılık geleneği denir.

Nogay Türklerinde, eğlenmek amacıyla herkes şın söyleyebilir. Fakat her şın söyleyene şınşı denilmez. Çünkü bunun için kişinin bazı özellikleri taşıması gerekir. Öncelikle şınşı kişinin çevresine göre daha bilgili, güngörmüş ve dolayısıyla toplumda sözüne itibar edilir kişi olması gerekir. Zira çevredeki kişilerin önemli bir işi olduğunda mutlaka konuyla ilgili şınşıların fikirleri alınır. Örneğin, bir kişinin evlenmek maksadıyla kızı istendiğinde kızın babası veya kız istemeye gitmeden önce damadın babası mutlaka, o bölgede değer gören bir şınşıya danışır ve onun öngörüleri dinlenir. Şınşıların bu özellikleri hayvan yetiştirilmesinde 
de çok önemsenir. Şınşılar, hayvanlar henüz küçükken ileride iyi veya kötü yönleriyle nasıl bir hayvan olacakları hakkında öngörülerde bulunurlar. Özellikle atlar arasından her yönüyle kaliteli atları seçebilmek çok becerikli şınşıların işidir. Çok eskiden çocukların bazı özelliklerine bakarak gelecekleriyle ilgili öngörülerde bulunan şınşılar da olmuştur (Kızıldağ, 2016).

Nogay Türklerine ait olan Mamay Destanı’nın kahramanlarından biri olan “Asan Abız” tipik bir şınşı özellikleri taşımaktadır. Aşım Sıkaliyev’in derlediği destana göre, Musa Bey isminde İdil'de rahat bir hayat sürdüren yaşlı bir adam vardır. Bu adamın, yedisi bir eşten ve beşi başka bir eşten olmak üzere on iki oğlu vardır. Musa Bey önemli işlerini her zaman Asan Abız'a danışarak yapar. Musa Bey kendisi öldükten sonra gelecekte oğullarının nasıl karakterlerde kişiler olacağını öğrenmek ve birbirleriyle kavga etmelerini önlemek için onları Asan Abız'a imtihan ettirmek ister (Temur, 2014: 28). Bu durum destanda şöyle geçer:

"Dos men seni şakıruvımnın nedeni, balalardı saga sınatayak bolaman. Nawlar össe kalay şıgayakken. ...Er kılığına köre, haysiyetine köre kadiy yaşayak. Nawlardın turuwu men vasiyetimdi aytıp ketsem kerek. "(Kalenderoğlu, 2010: 79).

Gece çocuklar uyuduktan sonra Asan Abız çocukların yatış şekillerini bir kâğıda çizer. Ertesi gün çocukların gelecekte iyi veya kötü yönleriyle nasıl insan olacaklarını Musa Bey’e söyler. Buna göre en akıllı çocuk Mamay olacaktır.

Şınşılar bazı özellikleriyle çok eski dönemlerde Türklerde bulunan kamlara benzerler. Temur'a göre, eski Türkler gelecekle ilgili iyi ve kötü haberleri kamlardan öğrenirlerdi. Onların tavsiyelerini almadan orduyu toplamaz ve savaşa gitmezlerdi. Kamlar doğan çocukların kaderleri hakkında da fikir verirlerdi. Hanlara kendisinden sonra ili yönetecek çocukların nasıl yönetecekleri konusunda hana bilgi verirlerdi (Temur, 2014: 27).

Şınşılar yine gelecekten haber verme ve çevresi tarafından sözüne itibar edilme yönleriyle, Türk edebiyatında büyük öneme sahip olan, Dede Korkut Kitabı'ndaki Korkut Ata’ya benzerler. Dede Korkut Kitabı'nın giriş kısmında Korkut Ata ile ilgili geçen şu ibareler düşüncemizi destekler niteliktedir:

“...Korkut Ata derler, bir er ortaya çıktı. O, Oğuz’un en bilge kişisiydi. Oğuz'un içinde ermiş olduğu bilinirdi. Ne derse olurdu. Gaipten türlü haber söylerdi...” (Ergin, 1969: 1).

Şınşıların bir diğer özellikleri de belagat sanatına hâkim olmalarıdır. Bir kişinin kendisini şınşı olarak ispat edebilmesi için toylar, hıdırellez şenlikleri veya köy meydanları gibi insanların toplandığı yerlerde şairlik kabiliyetini göstermesi gerekir. Bu gösteri genelde başka bir şınşıyla atışma şeklinde doğaçlama söylenen şınlarla yapılır (Kızıldağ, 2016). Nogaylarda şınların atışma şeklinde dile getirilmesi ve buna benzer atışma örneklerinin Divanu Lûgati’t-Türk’te de bulunması Türk boylarının ortak sözlü edebiyat geleneğine bağlı olduğunun ispatıdır.

\section{III. Şınların şekil ve içerik özellikleri}

$\mathrm{Bu}$ bölümde sunduğumuz bilgiler için Nogay köylerinde yaşayan yedi kaynak şahıstan toplam elli üç beyit şın derledik. Ancak bu şınlardan bazıları farklı kaynak şahıslardan derlenen aynı şınlardır. Bu çalışmamızda otuz sekiz farklı şın örneği bulunmaktadır.

Nogay Türklerinin sözlü edebiyatında büyük bir öneme sahip olan şınların nazım birimi beyittir. Ölçüsü ise genellikle on birli hece ölçüsüdür. 
Bismillah birdir Allah biz basliyak, Lakırdadı taslıyak şın basliyak.

Şılap şınşı tulman şılnlasam koymam, Sendeylerdi şınlatıp karap turmam.
Bismillah birdir Allah biz başlayalım, Lakırdıyı bırakalım şına başlayalım.

Şınşı değilim ama şın söylesem susmam Senin gibileri söyletip bakıp da durmam

Nadir de olsa on dörtlü hece ölçüsüyle söylenen şınlar da mevcuttur.

Kara guz terekte kanadin caygan erekke,

Süygen gizım ene tayanip turgan tirekke.

Ala tana aylangan argawulga baylangan, Şekerdin gizları bargan bayına baylangan.
Kara kız kanadını koymuş erik ağacına

Sevdiğim kız işte dayanıp duruyor direğe

Ala danam dolanmış karşıya bağlanmış

Şeker'in kızları kocasına bağlanmış

Şınlarda her beyit diğer beyitlerden farklı olarak kendi içinde kafiyelidir. Bu çok seslilik düzeniyle kulağa hoş gelen bir ahenk sağlanmış olur. Kafiye çeşitlerinin tamamı ile şın söylenebilir. Fakat genellikle tam kafiye kullanılır. Kafiyelerin yanında redifler de bulunabilir. Bazılarında ise kafiye olmadan sadece redifler bulunur.

Segiz ögüz say saban saldım ızga,

Kelinşektın aruwun degisbem gızga.

(-ga: redif, -1z: tam kafiye)

Kisga ayaklı kız balam yarım cürek,

Atasinıı üyüne kim bolgan tirek.

(-rek: zengin kafiye)

Terezeden karaysın köramaysın,

Carım okka şitlewük beramaysın.

(-amaysın: redif, -r: yarım kafiye)
Sekiz öküzü pullukla gönderdim tarlaya

Gelinin iyisini değişmem kendi kızıma.

Küçük kız çocuğum yarım yürek

Babasının (dedesi) evine kim olmuş direk.

Pencereden bakıyorsun göremiyorsun

Yarım okka çekirdek veremiyorsun.

Şınların bazılarında ilk mısra doldurma dizedir. Asıl duygu ve düşüncenin verildiği ikinci dizeye hazırlık veya kafiyeyi doldurmak amacıyla söylenir. Anlam bakımından ikinci mısra ile pek bağlantılı değildir.

Erteşekten tuwgan culdızga men ay dedim

Erteşekten beri şınlayman sen kaydedin.

Ündürükde bulamı, işinde semser kassık

Men senmen şılamam awzun sasık.

Kül töböden clynadım curun murun

Men senmen şılamam şoşka burun.
Erkenden doğan yıldıza ben ay dedim

Erkenden beri şınlıyorum sen nerdeydin.

Mutfak dolabında bulamık içinde kaşık

Ben sana şın söylemem ağzın kokuyor.

Kül tepesinden biriktirdim deri parçası

Ben sana şın söylemem domuz burun .

Şınların bazılarında ise ilk dize doldurma dize olmayıp anlam bakımından ikinci mısra ile birbirini tamamlar. Bu şekilde olan şınlarda dizeler duygu ve düşünce açısından bir bütünlük arz eder. 
Ayttırayım atandan berse alayım,

Canıı süygen cerlerge üy salayım.

Aksam bardım sizge cok edin üyde,

Cibek şalı ilüwlüdü üsküyde.
Seni babandan isteteyim verirse alayım

Canının istediği yerlere ev yaptırayım.

Akşam gittim size ama sen yoktun evde

İpek şalın asılıydı iç odada.

Şınşıların izleyiciler önünde atışmak maksadıyla söyledikleri şınlar çoğunlukla hoş sözler ve iltifatlarla başlar. Daha sonra karşıdaki şın söyleyen kişiyi yenebilmek için söylenen ve hiciv içeren şınlarla devam eder. Şınşıları izleyen topluluk çok eğlenir ve şınşıları ilgiyle dinler.

1.Şınş1: Bismillah birdir Allah biz basliyak,

Lakırdadı tasliyak şınga baslıyak.

2.Şınşı: Şınla denız şınlayı k aşılayık Aldınızka gul bolup şaşılayık.

1.Şınşı: Toru atımdı iyerlep saldım tüzge Can yoldasim bolur dep keldim sizge.

2.Şınş1: Kelgen bosan hoş keldin otur tizime Bazı dalgın bolurman karama sözüme.

1. şınş1: Şınlasam ah temırden pala etermen Sendeylerge şınlasam alt etermen.

2.şınşı: Şınlasam şınşı tuvulman şınlap koymam Sendeylerdi şınlatıp karap da kalmam.

1.şınş1: Şakırsin koraz, atsın tan ayan bayan Şınşı kenindi bileyim tanga tayan

2.şınş1: Şın degeniy netkeşiy kiseden şıgar, Pehlivanlar küresse batırler cıgar.
Bismillah birdir Allah biz başlayalım, Lakırdıyı bırakalım şınlamaya başlayalım

Şın söyleyin diyin söyleyelim açılalım

Sizin önünüze gül olup saçılalım

Doru atımı hazırlayıp düze koydum

Can yoldaşım olursun diye geldim size

Geldi isen hoş geldin otur dizime

Bazen dalgın olabilirim bakma sözüme

Şınlasam ak demirden pala yaparım

Senin gibilere şın söylesem yenerim

Şın söylesem şıncı değilim ki susmam

Senin gibileri şınlatıp bakıp da kalmam

Çağırsın horoz doğsun güneş ayan beyan

Şıncı olduğunu bileyim sabaha kadar

Şın dediğin nedir ki, cebimden çıkartırım

Pehlivanlar güreşseler, yiğit olanı yener.

Nogaylarda köyde evlenme çağına gelmiş erkekler, kızlara duygularını ifade etmek için şın söyleyebilirler. Kızlar ise olumlu veya olumsuz düşüncelerini şın aracılığıyla belirtebilirler.

Erkek: Keşegımsin sen menim kerilgen ok day

Körünesin közümge elde cokday.

Kız: Üyündün aldına zerdalı ektim

Asga suwga karamay zarındl şektim.

Erkek: Aytırayım atandan seni berse alayım

Canın süygen cerlerge üy salayım.

Kız: Kök kögerşin bolayım konaklayım Senin salgan üyündü men aklayım.
Gelinimsin benim gerilmiş ok gibi

Görünüyorsun bana başkasında yok gibi

Senin evinin önüne kayısı ektim

Aşa suya bakmadan derdini çektim.

İsteyeyim babandan seni verirse alayım

Canının istediği yerlere ev koyayım

Mavi güvercin olayım evine konuyum

Senin koyduğun evi ben aklayım 
Erkek: Eki közlü üy saldım bölüyekben Awurup senin dertinden ölüyekben.

Kız: Kıska ayaklı gız balam carım cürek Atasının üyüne kim bolgan tirek.

Erkek:Kaytarayım avleye gaz kapayım Köyülde bar kolda cok napayım?

Kız: Heş bir malıy cok bossa sal bir avle, Bir de biz tilesek berir Mevla.

Erkek: Enşe şette üyün bar tas kalawl, Baramayman üyünge it baylawl.

Kız: Enşe şette üyüm bar kel de tokta, Atınga cüven bolayım kümüsten nokta.

Erkek: Koy avledin işinde koyduך $ı z l$, Kongurav sesli, dal pesli, baydin gizi.

Kız: Sen üyüme kelgende koy soyarman, Saluwlu tösek salkım üy bas koyarman.

Erkek: Şıbarala şıt şıba kus konganday, Seni canım bek süydü dos bolganday.

Kız: Enşeşette üyüm bar kele ketsen, Şekerden şerbet eteyim işe ketsen.

Erkek: Argawuldan aylangan ala tanam, Beresege glz berse al diydi anam.

Kız: Argawuldan aylangan ala tanam, Beresege giz bolmaz cok diydi anay.

Erkek: Koy awlediๆ işinde koy kumalak, Men nişanlımdı kördüm tıptımalak.

Kı: Kasık börek eteyim kasımdı gerip, Kayınbiken bolayım sinnimdi berip. Erkek: Segiz ögüz saysaban, tez kaytaman, Tösü töbeli aruw giz saga aytaman.

Kız: Şıktım taw basga bay köründü, Bıttınıkiy aklım dört bölündü.
İki gözlü ev yaptım böleceğim

Hastalanıp senin derdinden öleceğim

Küçük kız çocuğum yarım yürek

Babasının(dedesi) evine kim olmuş direk

Geri döndüreyim bahçene kaz koyayım

Gönülde var elde yok ne yapayım

Hiçbir malın yoksa yap bir bahçe

Bir de biz istersek verir Mevla

Kenarda evin var taş duvarlı

Gidemiyorum senin evine köpek bağlı

Kenarda evim var gel de dur

Atına yular olayım gümüşten nokta

Koyun bahçesinin içinde koyunun izi

Güzel sesli, dal fesli zengin kızı

Sen evime gelince koyun keserim Yaptığım yatağa baş koyarım

Çatıya kuş konduğu gibi

Seni çok sevdim dost gibi

Kenarda evim var gelip gitsen

Şekerden şerbet yapıyım içip gitsen

Karşıdan dolanmış ala danam

Veresiyeye kız verirlerse al diyor anam

Karşı̀dan dolanmış ala danam

Veresiyeye kız olmaz, yok diyor anan

Koyun bahçesinin içinde koyun birikintisi

Ben nişanlımı gördüm, yusyuvarlak

Kaşık börek yapıyım kaşımı gerip

Baldızın olayım bacımı verip

Sekiz öküzlü pullukla tez dönüyorum

Göğsü iri güzel kız sana söylüyorum

Çıktım dağ başına adam göründü

Azıcık aklım dörde bölündü. 


\section{Sonuç}

Türk lehçelerinde şın sözcüğü doğru, gerçek, tenkit, ideal olan anlamlarını taşımaktadır. Şınşı sözcügü ise gerçekleri söyleyen, insanlar ve hayvanların dış özelliklerine göre kalitesini ön görebilen, gelecek hakkında tahminlerde bulunan kişi ve ses çıkartan kişi anlamlarını taşımaktadır. Eski Türkçe metinlerde sın- "kırıl-" ve sın "mezar, kabir" anlamlarında kullanılan sözcüğün konumuz olan şın sözcüğü ile ilişkili olamayacağını düşünmekteyiz. Sözcüğün Kutadgu Bilig'de geçen boy bos, kılık anlamının; şınşıların insanların ve hayvanların dış görünümlerine göre tahminlerde bulunma anlamı ile ilişkili olabileceğini temkinli bir şekilde düşünmekteyiz.

Nogay Türklerinde şın, Türk Halk Edebiyatında âşıkların atışmalarda kullandıkları dizelere benzeyen fakat dörtlükler yerine beyitlerle söylenen, kendine özgü çeşitli şekilsel özellikleri bulunan ve belli bir gelenek içinde gelişen bir nazım şeklidir. Hecenin genellikle on birli ölçüsüyle ve az da olsa on dörtlü ölçüsüyle söylenirler. Birçok kafiye çeşidiyle şın söylendiği tanıklanmıştır. Beyitler genellikle kendi içinde kafiyelidirler. İlk beyitler bazen doldurma dize olarak kullanılır bazense dizeler anlam bütünlüğü içerisindedir.

Amacına göre genel olarak şınlar, şınşıların karşılıklı olarak birbirlerine şın söyleme maharetlerini göstermek amacıyla söyledikleri ve erkek ile kızların birbirlerine sevgilerini ifade etmek için söyledikleri olmak üzere ikiye ayrılabilir. Şın nazım türünü söyleyen şınşıların geleceğe dair tahminlerde bulunabilme, bilgili olma, sözüne itibar edilme ve güzel söz söyleyebilme gibi özellikleri vardır.

Derleme yaptığımız Nogay Türklerinde şınşılık geleneği günümüzde yok olmaya yüz tutmuştur. Artık bu gelenek, geçmişte şınşıların söyledikleri beyitlerin çeşitli sohbet ortamlarında, toylarda ve şenliklerde söylenmesiyle yaşatılmaya çalışılmaktadır. Bu şınlar da yazıya aktarılmadığ 1 için şahısların zihinlerinde zamanla kaybolmaktadır.

Şın ve şınş1 kelimesinin diğer Türk lehçelerinde küçük ses değişiklikleriyle de olsa kullanılması Türk boylarının ortak sözlü edebiyat geleneğine bağlı olduğunu gösterir. Şınlar sosyal yaşantıda insanlar arasında birleştirici etkisinin bulunması, geleneklerin devam etmesi hususunda önemli rol oynaması, törelerin kökleşmesini sağlaması ve kültürel özelliklerin yansıtılmasına aracı olması yönüyle çok önemli bir kültür değeridir. Nogay Türkleri gibi nüfus sayısı bakımından gittikçe azalan bir topluluğun sözlü edebi ürünlerinin incelenmesi, o toplumun Türk dünyasında unutulmaması için oldukça önemlidir.

\section{Kaynaklar}

Arat, R. R. (1979). Kutadgu bilig III (İndeks). (haz. K. Eraslan, O. F. Sertkaya, N. Yüce). İstanbul: T.K.A.E.

Aydın, E. (2013). Tariat ve Xi'an (Karı Çor Tegin) yazıtları 1şı̆̆ında sın 'mezar' sözcüğü üzerine. Belleten, Ankara: 61-2, s.161-166.

Azar, B. (2007). Sözlü kültür geleneği açısından Türk saz şiiri. F. Ü. Sosyal Bilimler Dergisi, Elazığ:17-2, s. 119-133.

Baskakova, N. A. (1968). Nogaysko - Russkiy Slovar, Moskova.

Clauson, S.G. (1972). An etymological dictionary of pre-thirteenth-century Turkish, Oxford: Clarendon. Ergin, M. (1969). Dede Korkut kitabı. İstanbul: Milli Eğitim. 
Gabain, A. V. (1988). Eski Türkçenin grameri. (çev. M. Akalın). Türk Tarih Kurumu, Ankara.

Kalenderoğlu, İ. (2010). Mamay Nogay Türklerinin kahramanlık destanı. Ankara: Ena Grup.

Kaşgarlı M., Divanu lugati 't-Türk (Giriş-Metin-Çeviri-Notlar-Dizin), (2015). haz. A.B. Ercilasun ve Z. Akkoyunlu, Ankara: Türk Dil Kurumu.

Köprülü, F. (1989). Edebiyat araştırmaları I. Ötüken, İstanbul.

Mabrufaz, Z. B. (1981). Özbek tilinin izahlı lügati. C.II, Moskova; s. 53'ten aktaran, Temur, N. (2014). Kırgız Türklerinde sınçılık geleneği ve Kırgız sınçıları, Ankara: Türk Dil Kurumu.

Mevdudi, M. S., (2004). Tefhimu'l Kur'an meali. Konya: Yediveren.

Pekarskiy, E. K., (1945). Yakut dili sözlüğ̈̈. s. 221'den aktaran, Temur, N., (2014). Kırgız Türklerinde sinçılık geleneği ve Kırgız sınçıları. Ankara: Türk Dil Kurumu.

Siqaliyev, A. (1975). Sïnap qarap sïrlasïp, Çerkessk. s. 8'den aktaran: Akbaba, D. E., (2009), Nogay Türkçesi grameri, Ankara: Grafiker.

Tekin, T. (2003). Orhon Türkçesi grameri. (2. Bask1), İstanbul: Sanat.

Temur, N. (2014). Kırgız Türklerinde sınçılık geleneği ve Kırgız sinçıları. Ankara: Türk Dil Kurumu.

Yudahin, K. K. (1985). Kirgzsko-Russkiy Slovar1-2. Frunze; s. 180'den aktaran, Temur, N., (2014).

Kırgız Türklerinde sınçılık geleneği ve Kırgız sınçıları. Ankara: Türk Dil Kurumu.

\section{Kaynak Şahıslar}

Atılgan, Necmettin, dy: Doğankaya köyü/ Şereflikoçhisar/ Ankara, dt:1945, ilkokul mezunu.

Aytar, Nurettin, dy: Doğankaya köyü/ Şereflikoçhisar/ Ankara, dt: 1939, okur-yazar.

Benli, Hasan, dy: Seyitahmetli köyü/ Kulu/ Konya, dt: 1960, lisans mezunu.

Çağdaş, Raziye, dy: Akin köyü/ Şereflikoçhisar/ Ankara, dt:1937, okur-yazar.

Dağtekin, Mehan, dy: Doğankaya köyü/ Şereflikoçhisar/ Ankara, ilkokul mezunu.

Göçer, Ayşe, dy: Akin köyü/ Şereflikoçhisar/ Ankara, dt:1940, okur-yazar.

Kızıldağ, Hamza, dy: Akin köyü/ Şereflikoçhisar/ Ankara, dt:1960, ilkokul mezunu.

Kutlu, Şevki, dy: Doğankaya köyü/ Şereflikoçhisar/ Ankara, dt: 1927, ilkokul mezunu.

Özdere, Necmettin, dy: Kırkkuyu köyü/ Kulu/ Konya, dt: 1955, ilkokul mezunu.

Polat, Güley, dy: Akin köyü/ Şereflikoçhisar/ Ankara, dt:1933, mezuniyeti yok.

Şener, Şükrü, dy: Akin köyü/ Şereflikoçhisar/ Ankara, dt:1932, okur-yazar.

Yıldırım, Fatma, dy: Şeker köyü/ Şereflikoçhisar/ Ankara, dt:1926, mezuniyeti yok.

Yılmaz, Elmas, dy: Doğankaya köyü/ Şereflikoçhisar/ Ankara, mezuniyeti yok.

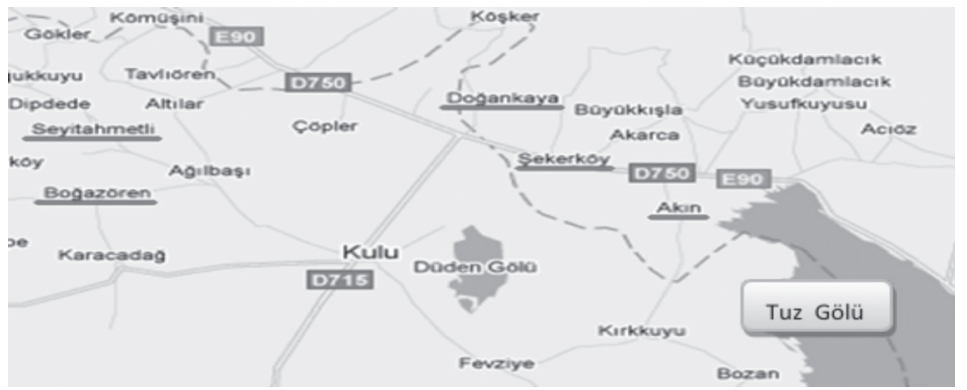

Şekil 1. Derleme yaptı̆̆ımız Akin, Doğankaya ve Şeker köyleri Ankara'nın Şereflikoçhisar ilçesine; Kırkkuyu, Seyitahmetli ve Boğazören köyleri ise Konya'nın Kulu ilçesine bağlıdır. 